\title{
Regulation of transcription factor AP-2 by the morphogen retinoic acid and by second messengers
}

\author{
Bernhard Lüscher, Pamela J. Mitchell, Trevor Williams, and Robert Tjian \\ Howard Hughes Medical Institute, Department of Biochemistry, University of California at Berkeley, Berkeley, California \\ 94720 USA
}

The expression of the transcription factor AP-2 recently has been shown to be enhanced during retinoic acid (RA)-induced differentiation of NT2 cells, a human teratocarcinoma cell line. Here we show that this induction of AP-2 mRNA is at the level of transcription and is transient, reaching a peak 48-72 hr after the addition of RA and declining thereafter, even in the continuous presence of RA. Increased levels of AP-2 mRNA are reflected in a similar elevation of AP-2 protein and accompanied by an increase in the AP-2-binding site-dependent transcriptional activity of a reporter gene. AP-2 also has been proposed to confer TPA and cAMP inducibility on promoters/enhancers containing AP-2-binding sites. We investigated the effect of these agents on the expression of AP-2 protein and mRNA. Our experiments demonstrate that expression of the AP-2 gene in HeLa cells is not elevated significantly by TPA or by a calcium ionophore and is not enhanced at all by agents that increase intracellular cAMP concentration. In fact, AP- 2 mRNA is repressed by both TPA and the calcium ionophore A23187 through a delayed response. These data suggest that the AP-2-binding site-mediated cAMP and TPA responses are not regulated at the level of AP-2 expression but, rather, achieved either by post-translational changes in AP-2 or in conjunction with another protein.

[Key Words: Transcription; retinoic acid-induced differentiation; TPA and cAMP response; post-translational regulation]

Received May 9, 1989; revised version accepted August 7, 1989.

Regulated gene expression during mammalian cellular differentiation requires alterations in the transcription rates of specific genes. This process depends on a continuous interplay between environmental and genetic factors. Some progress has been made in identifying proteins that are involved in transducing extracellular signals and mediating transcriptional changes. For instance, steroid hormones and many growth factors act in conjunction with specific receptors to enhance transcription of defined sets of target genes (for review, see Yamamoto 1985; Carpenter 1987; Evans 1988) and a variety of DNA-binding transcription factors have been proposed to function as nuclear targets for signals transduced in response to extracellular stimuli (Sen and Baltimore 1986; Treisman 1986; Chiu et al. 1987; Lee et al. 1987; Montminy and Bilezikjian 1987; Hyman et al. 1988; Miyamoto et al. 1988). Genes encoding some of these proteins have been cloned, and detailed characterizations are under way (for review, see Mitchell and Tjian 1989).

Retinoic acid (RA), the acidic form of vitamin A, can induce cellular differentiation of embryonic stem cells in tissue culture. It may also occur as a natural morphogen that forms a gradient involved in establishing the anterior-posterior pattern during chicken limb de- velopment (Thaller and Eichele 1987). The suggestion that RA may act in a manner analogous to steroid hormones was supported recently by the identification of specific intracellular RA receptors /Giguere et al. 1987; Petkovich et al. 1987; Benbrook et al. 1988; Brand et al. 1988). Many murine cell lines have been described to undergo distinct differentiation when treated with RA. The teratocarcinoma stem cell line F9, for example, undergoes synchronous differentiation into cells that resemble primitive extraembryonic endoderm of the mouse embryo (Strickland and Mahdavi 1978). Several genes have been identified that are not transcribed in undifferentiated F9 cells but are actively expressed after differentiation (Rosenthal et al. 1984; Sleigh and Lockett 1985; Chiocca et al. 1988; LaRosa and Gudas 1988; Rickles et al. 1989). Some of these genes apparently are turned on rapidly after the addition of RA by mechanisms that can occur in the absence of protein synthesis (Chiocca et al. 1988), but the majority respond with slower kinetics, implying that a hierarchy of steps is involved in cellular differentiation. Interestingly, some of the genes known to be activated during RA-induced differentiation contain sequences closely resembling the consensus DNA-binding site for transcription factor $\mathrm{AP}-2$, as, for example, the major histocompatibility 
complex (MHC) class I H2 genes (Kimura et al. 1986), the tissue plasminogen activator gene (Rickles et al. 1989), the Hox-1.6 gene (ERA-1, LaRosa and Gudas 1988), and the SV40 enhancer (Sleigh and Lockett 1985).

Extracellular stimuli can be transduced through a variety of cell-surface receptors, which activate second messenger pathways with diverse consequences in metabolic processes. Changes in the level of second messengers such as diacylglycerol (DAG) and cAMP, for example, lead to rapid activation of protein kinase $C$ - and A-signaling pathways, respectively and, in turn, to transcriptional stimulation of specific sets of genes (for review, see Nishizuka 1986; Roesler et al. 1988|. The tumor promoter TPA (12-O-tetradecanoylphorbol 13-acetate), a biologically stable analog of DAG, is used widely to study phenomena linked to activation of protein kinase C (Castagna et al. 1982) and is a potent activator of a variety of genes. Several DNA-binding transcription factors, including the AP-1 family, AP-2, AP-3, and NF-kB, have been implicated in mediating TPA responses (Chiu et al. 1987; Imagawa et al. 1987; Lee et al. 1987; Baeuerle and Baltimore 1988a), but little is known about the mechanisms by which these factors might accomplish the induction.

Genes that are induced transcriptionally by cAMP have been categorized recently into two major groups, according to the sequence of their essential cis control elements (Roesler et al. 1988). Group l consists of genes with cAMP-responsive elements (CREs) that closely fit the consensus DNA-binding sequence of the CRE binding protein (CREB). The recent cloning of CREB cDNAs (Hoeffler et al. 1988; Gonzalez et al. 1989) may help to resolve the role of this protein during cAMP regulation of its target genes. The second group of genes are those that are induced acutely by cAMP but apparently lack a consensus binding sequence of the CREB type. Interestingly, all these genes are characterized by the presence of an AP- 2 consensus binding site. This correlation strongly supports a role for AP-2 in the cAMP response. The cAMP-responsive control region of one gene, proenkephalin, contains several factor binding sites, including one for AP-2, that contribute incrementally to maximal cAMP induction (Comb et al. 1986, 1988; Hyman et al. 19881.

Transcription factor AP-2 was purified originally from HeLa cells as a $\sim 50-\mathrm{kD}$ protein that binds specifically to cis-elements within the simian virus 40 (SV40) and human metallothionein IIa (hMTIIA) enhancers; the purified protein was found to recognize sites with the consensus CCCCAGGC in a diverse group of other genes (Mitchell et al. 1987). Preliminary analysis using a cDNA encoding AP-2 led to the finding that AP-2 mRNA levels are elevated substantially after treatment of a human embryocarcinoma cell line with RA (Williams et al. 1988). This result suggested that AP-2 may play a crucial role in mediating transcriptional induction by RA. The work presented here is aimed at identifying changes in the AP-2 transcription factor, which could explain the described inductions of genes with AP-2binding sites. Detailed analysis of the AP-2 response to
RA treatment shows that the induction is transient and achieved by an elevated transcription rate of the gene. In contrast, we find that TPA and cAMP induction of AP-2-binding site-containing genes cannot be explained by gross quantitative or qualitative changes in AP-2 expression, implying that, in these cases, AP-2 activity is regulated by a post-translational mechanism or perhaps in conjunction with another protein.

\section{Results \\ Transient activation of AP-2 by RA-induced differentiation of NT2 cells}

Recently we showed that the mRNA of AP-2 was elevated following RA treatment of NT2 cells (Williams et al. 1988). These cells represent a subclone of the teratocarcinoma cell line Tera-2, which irreversibly differentiates into multiple cell types including neurons, upon addition of RA (Andrews 1984). To better define the response of AP-2 to RA, we analyzed AP- 2 mRNA levels in time course experiments (Fig. 1A). NT2 cells were treated with RA at $10^{-5} \mathrm{M}$, a concentration reported previously to induce differentiation, and cytoplasmic RNA was isolated after the times indicated. Control cells were treated in parallel with solvent alone. For the time points from 4 to 7 days, fresh medium with or without RA was added to the cells on day 3. Steady-state levels of AP-2 mRNA were determined in RNase protection assays using a probe derived from the AP- 2 cDNA clone. As an internal control, we also measured the mRNA level for transcription factor $\mathrm{Sp} 1$. Comparison of equal amounts of cytoplasmic RNA reveals that AP- 2 mRNA levels are clearly elevated after $24 \mathrm{hr}$ in the presence of RA and reach maximal levels after 2 days of induction (10- to 15-fold, Fig. 1A). No significant elevation of AP-2 mRNA was found at earlier time points of 3,6 , and $12 \mathrm{hr}$ (data not shown). Surprisingly, the AP-2 mRNA concentration decreased to basal level within a similar time span during longer incubation in the presence of RA. In contrast, the signal obtained for Spl mRNA remained constant under all conditions tested. Thus, the induction of AP-2 was transient, and medium renewal failed to prolong the RA response. As a positive control we quantitated Hox-2.1 transcripts in the same RNA samples in a parallel assay (Fig. 1B). Originally called $\mathrm{Hu}-1$, this homeo-box-containing gene was shown previously to be induced within 2 days after RA treatment of NT2 cells but remained induced for at least 10 days (Hauser et al. 1985). The time courses of RA-induced expression of AP-2 and Hox-2.1 were superimposed graphically in Figure 1C, using the signals obtained for $\mathrm{Spl}$ as internal standard. As expected, Hox-2.1 transcripts were still elevated at time points where AP- 2 mRNA was reduced to basal level. Hox-2.1 seems to be induced with slightly slower kinetics than AP-2 and therefore may constitute a potential target gene for transcriptional activation by AP-2.

To test whether the induction of AP-2 expression could also be observed at more physiological concentra- 

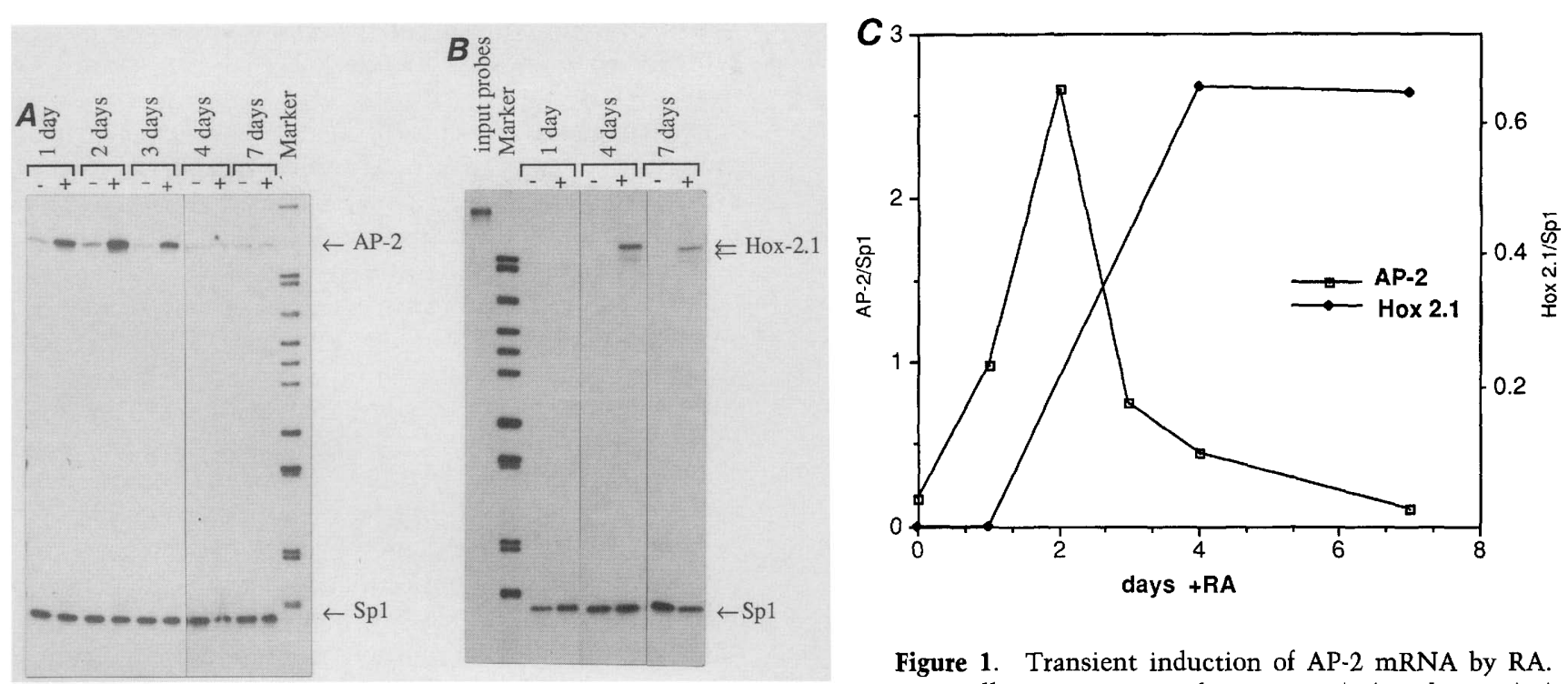

Figure 1. Transient induction of AP- 2 mRNA by RA. NT2 cells were grown in the presence $(+)$ or absence $(-)$ of RA $\left(10^{-5} \mathrm{M}\right)$. For the time points 4 and 7 days, the cells were passaged on day 3 and fresh medium with or without RA was added. Cytoplasmic RNA was isolated at the times indicated and subjected to RNase protection analysis. (A) RNA samples $(20 \mu \mathrm{g})$ were analyzed using riboprobes specific for AP-2 and Sp1 mRNAs. $(B)$ RNA samples $(5 \mu \mathrm{g})$ corresponding to the 1-, 4-, and 7-day time points in $A$ were analyzed with probes specific for Hox-2.1 and Spl mRNAs. $(C)$ RNA levels in $A$ and $B$ were quantitated by densitometric scanning, using the Spl-specific bands as internal controls; the data obtained for AP-2 and Hox-2.1 are superimposed graphically . (D) Dose-response time course of AP-2 inductions in response to RA. NT2 cells were incubated in the absence (-) or presence of $10^{-8} \mathrm{M}, 10^{-7} \mathrm{M}, 10^{-6} \mathrm{M}$, or $10^{-5} \mathrm{M} \mathrm{RA}$ for the days indicated. Cells harvested on day 4 and day 6 were passaged on day 3 and cultured with fresh medium. Cytoplasmic RNA was isolated and analyzed by RNase protection using probes specific for AP-2 and Spl (see Materials and methods).

tions of RA, we repeated the time course experiments, varying the RA concentration over four orders of magnitude (Fig. 1D). NT2 cells were incubated with RA at $10^{-5}, 10^{-6}, 10^{-7}, 10^{-8} \mathrm{M}$ or without RA and harvested after 1, 2, 3, 4, or 6 days. Cytoplasmic RNA was isolated and AP-2 and Spl mRNA levels were analyzed by RNase protection. The data in Figure 1D show that AP-2 mRNA induction at $10^{-6} \mathrm{M}$ RA was very similar to that at $10^{-5} \mathrm{M}$ (cf. lanes 4 and 5, 9 and 10, 14 and 15). AP-2 was induced severalfold even at the lowest concentration tested $\left(10^{-8} \mathrm{M}\right.$, cf. lanes 11 and 12$)$, albeit with somewhat slower kinetics than at higher concentrations. Maximal induction of AP-2 mRNA at $10^{-7} \mathrm{M}$ RA was slightly lower than at $10^{-6} \mathrm{M}$. However, the inductions were transient at all the concentrations tested; the AP-2 mRNA concentration peaked and began to decline within 3 days and reached basal levels at the latest by day 6 of continuous treatment with RA (lanes 19 and 20).

Using antibodies directed against an AP-2 peptide, we also monitored AP-2 protein in nuclear extracts of uninduced and 3-day RA-induced NT2 cells. As shown in Figure 2 the changes in the AP-2 RNA level were reflected in a similar, 10- to 15-fold induction of the AP-2 protein. After this period of RA treatment, the level of AP-2 protein was similar to that seen in untreated HeLa $\mathrm{tk}^{-}$cells (Fig. 2), which is in agreement with the AP-2 RNA levels observed in the two types of cells (data not shown). These data suggest that transcription factor AP-2 may play an important, although transient, role in the differentiation of NT2 cells by affecting AP-2-responsive genes.

To determine whether RA induction of AP-2 mRNA and protein leads to changes in the expression of target genes, we performed transient expression experiments to look for an increase in AP-2-binding site-dependent transcription. Two different reporter genes were used for these experiments (Fig. 3A). The plasmid pMCAT3, used as a negative control, contains the chloramphenicol acetyltransferase (CAT)-coding region driven by a truncated 


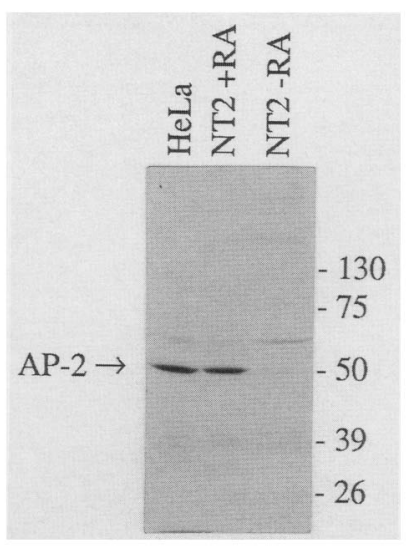

Figure 2. RA induction of AP-2 protein. NT2 cells were cultured in the presence $\left(+\mid\right.$ or absence $\left(-\mid\right.$ of $10^{-5} \mathrm{M}$ RA for 3 days, and HeLa tk- cells were grown in parallel for comparison. Nuclear extracts were subjected to Western blot analysis and AP-2 protein quantitated using affinity-purified antiserum directed against an amino-terminal AP-2 peptide.

hMTIIA promoter. p(AP-2) ${ }_{5}$ MCAT3 is a derivative of pMCAT3, which contains five tandem copies of an AP-2-binding site derived from the SV40 enhancer inserted just upstream of the hMTIIA promoter. pMCAT3 and $\mathrm{p}(\mathrm{AP}-2)_{5} \mathrm{MCAT} 3$ were transfected independently into NT2 cells, followed by incubation of the cultures in the presence or absence of RA $\left(10^{-6} \mathrm{M}\right)$ for $48 \mathrm{hr}$. Cyto- plasmic RNA then was isolated and examined by RNase protection assays, using three probes specific for mRNA from the AP-2 and $\mathrm{Sp} 1$ genes and transcripts from the transfected pMCAT reporter (Fig. 3B). Without RA treatment, the levels of specifically initiated transcripts from pMCAT3 were very low; the transcripts from p(AP-2) ${ }_{5}$ MCAT3 were low, but detectable, reflecting the low abundance of AP- 2 mRNA and protein in these cells (Fig. 3B, lanes 1 and 3). However, treatment with RA resulted in an appreciable elevation of AP- 2 mRNA levels and in enhanced transcription from the AP-2-binding site-containing reporter gene $\mathrm{p}(\mathrm{AP}-2)_{5} \mathrm{MCAT} 3$, relative to the enhancerless pMCAT3 construct (cf. lanes 2 and 4). The levels of $\mathrm{Sp} 1 \mathrm{mRNA}$ were unaffected by RA treatment (lanes $1-4$ ). These results suggest that the newly synthesized AP- 2 protein is transcriptionally active and that RA induction of AP- 2 can readily lead to activation of AP-2-dependent target genes. The accumulation of AP-2 protein is likely to be somewhat delayed relative to the peak of AP- 2 mRNA induction; thus, the activity measured at $48 \mathrm{hr}$ of RA treatment may not represent the maximal level of AP-2-binding site-dependent transcriptional activation that occurs during this transient induction.

\section{$R A$ induces AP-2 at the transcriptional level}

We performed nuclear run-on experiments to test whether the RA-mediated induction of AP-2 was the re-
A.
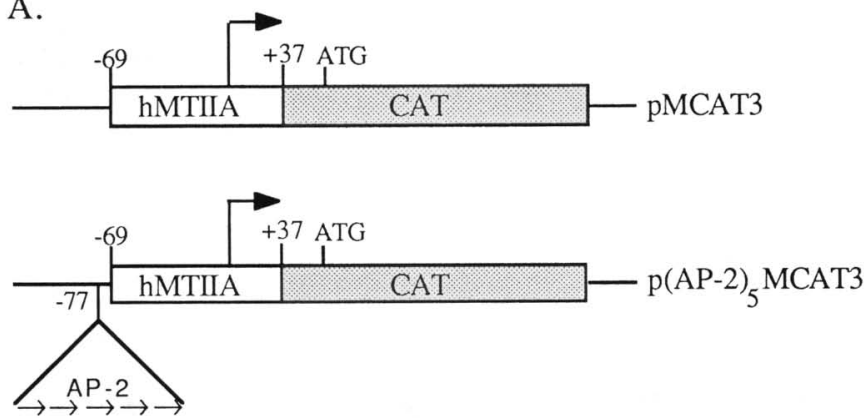

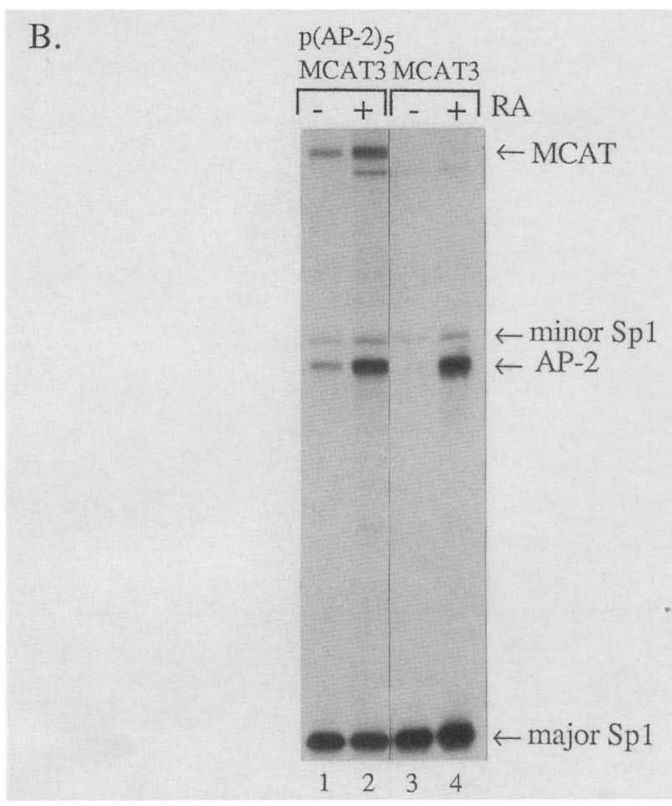

Figure 3. AP-2-binding site-dependent reporter gene responds to RA treatment during transient expression in NT2 cells. $(A \mid$ The structure of the two plasmids used for transfection is represented diagrammatically. pMCAT3 bears the coding region of the CAT gene linked to a truncated hMTIIA promoter lacking upstream enhancer elements. $\mathrm{p}(\mathrm{AP}-2)_{5} \mathrm{MCAT} 3$ contains five tandem AP-2binding sites from the SV40 enhancer inserted just upstream of the hMTIIA promoter of pMCAT3. (B) NT2 cells were transfected with pMCAT3 or p(AP-2) ${ }_{5}$ MCAT3 and incubated in the presence $(+)$ or absence $(-)$ of $10^{-6} \mathrm{M}$ RA for 48 hr. Cytoplasmic RNA was isolated and subjected to RNase protection analysis, using probes specific for endogenous Spl and AP-2 and for transcripts from the transfected pMCAT reporter plasmids. The two protections seen with the Spl probe (major and minor) correspond to two different forms of the Sp1 RNA. Protected bands specific for AP-2 and pMCAT reporter transcripts are also indicated. 
sult of changes in the transcription rate of the AP-2 gene or of post-transcriptional alterations affecting the halflife of AP-2 mRNA (Fig. 4). NT2 cells were grown in the presence or absence of RA for $36 \mathrm{hr}$, and nuclei were isolated as described in Materials and methods. Run-on transcripts were assayed by hybridization to filter-bound single-stranded DNA probes specific for AP-2 and several other reference genes, including CTF/NFI, Spl, actin, iun, and myc. The probe designated AP-2(1) corresponds to the protein-coding region of the AP-2 cDNA (Williams et al. 1988); the probe designated AP-2(2) was derived from a genomic intron sequence upstream of the AP-2 protein-coding region (B. Lüscher, unpubl.). As shown in Figure 4, the hybridization signals obtained for the exonic and intronic AP-2-specific probes were elevated substantially by RA-induced differentiation. These results strongly suggest that the induction of AP-2 mRNA by RA occurs largely at the level of transcription of the AP-2 gene. Interestingly, the signal from the AP-2(2) probe was stronger than that of AP-2(1), consistent with the idea that initiated RNA polymerase complexes were more abundant in the promoter-proximal region of AP-2, possibly due to transcription attenuation effects. In contrast to AP-2, none of the tested reference transcription factor probes gave an elevated hybridization signal in response to RA, confirming that the effect on AP-2 was selective. As the expression levels of AP-2 before induction were barely detected over background (cf. mp9 and AP-2 signals in Fig. 4), it

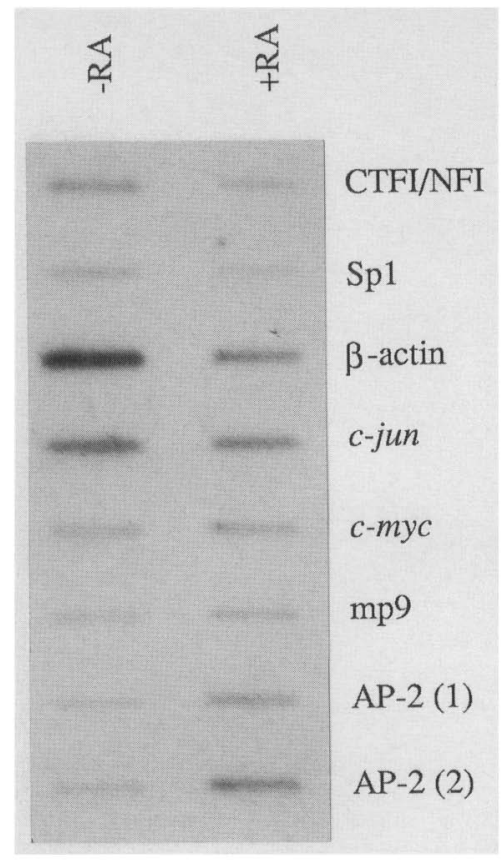

Figure 4. Transcriptional analysis of RA response in NT2 cells. Cells were grown in the presence $(+)$ or absence $(-)$ of $\mathrm{RA}$ for $36 \mathrm{hr}$ and subjected to nuclear run-on assays, as described in Material and methods. Single-stranded DNA probes bound to nylon membrane filters were hybridized with ${ }^{32} \mathrm{P}-\mathrm{la}$ beled transcripts and analyzed by autoradiography. was difficult to estimate the level of induction; however, the observed transcriptional response could easily account for most, if not all, of the 10- to 15 -fold induction in steady-state AP-2 mRNA.

\section{AP-2 $\mathrm{mRNA}$ is down-regulated by delayed responses to TPA and calcium ionophore}

Transcriptional induction by TPA is thought to be achieved through changes in the activity of one or more factors that bind TPA responsive cis-elements. These factors may be regulated at transcriptional, post-transcriptional, or translational levels to mediate the effect of TPA. Alternatively, for certain genes, where the response to TPA is very rapid and independent of protein synthesis, it is likely that post-translational modification of pre-existing factors is occurring. To assess the degree to which the AP-2-binding site-mediated TPA response may be achieved by changes in expression of AP-2, we measured AP-2 mRNA levels in HeLa tk ${ }^{-}$cells after treatment with TPA over a time course from 30 min to $8 \mathrm{hr}$ (Fig. 5A). Cytoplasmic RNA was isolated, and AP-2 and Spl mRNAs were quantitated in RNase protection assays. Interestingly, only a very small, but reproducible, 1.5-fold induction of the AP-2 mRNA was detected after $1 \mathrm{hr}$ in the presence of TPA /cf. lane 9 and 81 ; no increase at all was seen at the other time points tested. In a similar time course, a reporter gene containing an AP-2-binding site-dependent promoter has been shown to be induced severalfold by TPA treatment of HeLa cells (Chiu et al. 1987; Imagawa et al. 1987; Hyman et al. 1989). In contrast, we found that the level of AP-2 RNA was repressed three- to fivefold after prolonged exposure of HeLa cells to TPA $/ 8 \mathrm{hr}$, Fig. 5A, lane 23). The level of $\mathrm{Sp} 1 \mathrm{mRNA}$ did not change in response to TPA and thus served as a useful internal reference.

In parallel experiments, the effect of elevated calcium on expression of AP-2 was tested. As shown in Figure $5 \mathrm{~A}$, the response to treatment with the calcium ionophore A23187 was similar to the effects of TPA in that it resulted in delayed repression of AP- 2 mRNA/cf. lane 25 and 22) and virtually no short-term induction (cf. lane 4 and 1, lane 11 and 8, lane 18 and 15). When HeLa cells were treated with TPA and A23187 simultaneously, the individual responses were additive (lanes $9,10,11$ or lanes $23,24,25$ ), suggesting that separate mechanisms specific to TPA and A23187 are responsible for the marginal AP-2 inductions after $1 \mathrm{hr}$ (lanes 9 and 11) and the AP-2 repressions after $8 \mathrm{hr}$ (lanes 23 and 25). As a positive control, c-jun transcripts were quantitated in the same RNA samples using a genomic probe that spans the RNA start sites of the c-jun gene (Fig. 5B). Expression of c-jun (lanes 1, 8, 15, and 22) was barely detectable at basal level but was elevated rapidly in response to TPA (lanes 2, 9, 16, and 23), as reported previously (Angel et al. 1988). Furthermore, in a similar time course, c-jun was also induced by A23187 (lanes 4, 11, 18 , and 25). As was the case for the AP- 2 repressions, the c-jun inductions by TPA and A23187 were additive (lanes 3,10, 17, and 24). 


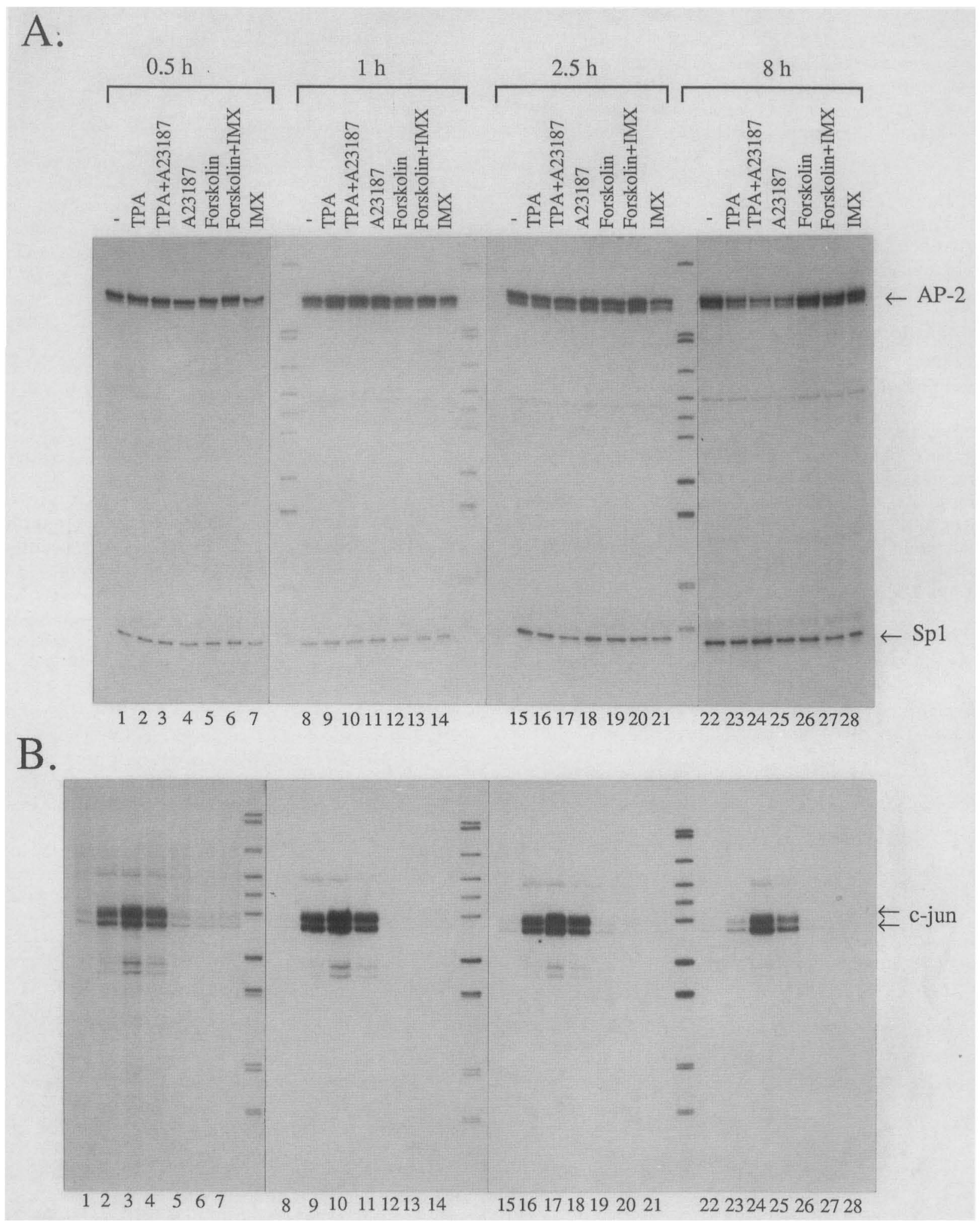

Figure 5. Responses of AP-2 and c-jun to induction by TPA, calcium ionophore A23187, forskolin, and IMX in HeLa tk ${ }^{-}-$cells. $(A)$ Cells were treated with solvent alone (lanes 1, 8, 15, and 22), with TPA, TPA + A23187, A23187 alone, forskolin, forskolin + IMX, or IMX alone, as shown above each lane. Cytoplasmic RNAs were isolated at the times indicated and analyzed by RNase protection, using riboprobes specific for AP-2 and Spl. Twenty micrograms of RNA was used for each assay. (B) The same RNA samples as in $A$ were analyzed by RNase protection using a probe specific for c-jun mRNA $5^{\prime}$ ends and $10 \mu \mathrm{g}$ of RNA for each assay. 
These data suggest that the increase in AP-2-binding activity in response to TPA, which has been reported by others (Chiu et al. 1987), is largely due to translational and/or post-translational alterations in AP-2 protein and not to changes in the expression of the AP-2 gene. Alternatively, it cannot be excluded that another protein distinct from AP-2 mediates the AP-2-binding site-dependent TPA response of reporter genes (see Discussion).

\section{The level of AP-2 mRNA remains unchanged after treatment of HeLa cells with cAMP}

In addition to TPA induction, AP-2-binding sites are also believed to mediate transcriptional responsiveness to elevated cAMP (Imagawa et al. 1987; Hyman et al. 1989). Therefore we tested whether there was any change in expression of the AP-2 gene in response to stimulation with forskolin and/or 3-isobutyl-1-methylxanthine (IMX). These agents are known to lead to a rapid increase in intracellular cAMP by activation of adenylate cyclase and inhibition of phosphodiesterase, respectively. As shown in Figure 5 (lanes 5-7, 12-14, 19-21, and 26-281, there was no induction of AP-2 mRNA by forskolin or by IMX nor by the two agents together at any of the time points tested. Thus, as in the case of induction by TPA and A23187, the AP-2-mediated cAMP response is likely to be the result of translational or post-translational changes affecting the AP-2 protein.

In preliminary immunoblotting experiments to test for translational and/or post-translational changes of AP-2 in response to TPA, calcium ionophore, and forskolin, we analyzed AP-2 protein in crude HeLa nuclei extracts using affinity-purified antibodies directed against an amino-terminal AP-2 peptide (Fig. 6). The delayed TPA- and calcium-dependent repression seen at the level of AP-2 mRNA was reflected in similar slight reductions in the amount of AP-2 protein (Fig. 6). However, no major changes were evident in the amount or in the relative mobility of AP-2 within $2.5 \mathrm{hr}$ after induction (data not shown). Identical results were also obtained using an antiserum directed against a carboxy-terminal peptide of AP-2 (data not shown). Although this technique is suitable to detect gross changes in protein quantity and quality, it does not allow us to make any conclusions regarding subtle changes in AP-2 during the course of cellular signal transduction.

\section{Discussion}

Our present study demonstrates that the mRNA of transcription factor AP-2 is transiently induced by RA and that this induction is achieved by changes in transcription of the gene rather than at the post-transcriptional level. The transient nature of the induction is observed at both high and low concentrations of RA and is therefore unlikely to be due to side effects of toxicity. We propose that AP-2 may be part of a cascade of regulatory genes that are sequentially activated during RA-induced differentiation. Elevated AP-2 levels are apparently not

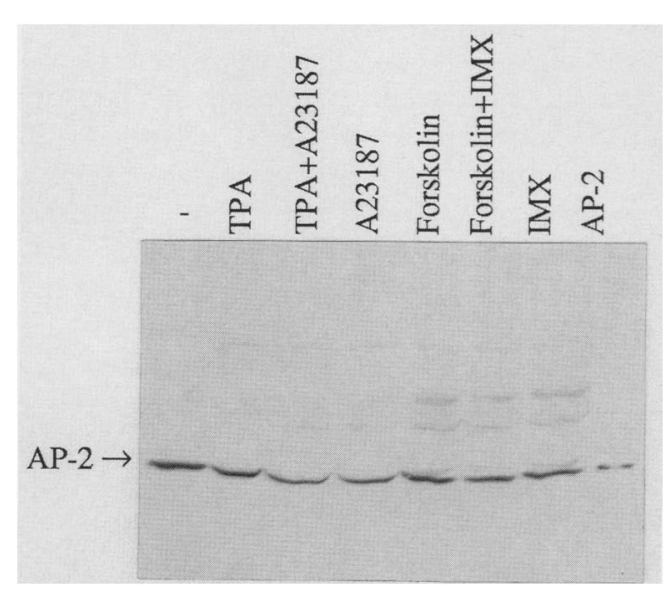

Figure 6. AP-2 protein levels in response to induction by TPA, calcium ionophore A23187, forskolin, and IMX. HeLa tk ${ }^{-}$cells were treated as in Fig. 5 for $8 \mathrm{hr}$, and total nuclear protein was analyzed by Western blotting, using an antiserum against an amino-terminal AP-2 peptide. (Lane $A P$-2) AP-2 protein purified to homogeneity by DNA affinity chromatography.

permanently required during differentiation of NT2 cells, but AP- 2 could serve as a genetic switch to turn on other trans-activators, some of which may be positively autoregulated. A good candidate for such a positively autoregulated gene that contains AP-2-binding sites is another transcription factor, c-iun (Angel et al. 1988); it has been suggested that c-jun may support its own expression after an initial transcriptional activation event.

Recently identified RA receptors (RAR), by analogy to structurally related steroid and thyroid hormone receptors, are likely to be DNA-binding factors involved in mediating primary transcriptional responses to RA (Evans 1988). The $\alpha$ RAR has been shown in DNA transfection experiments to activate transcription of a reporter gene with a binding site for the related thyroid hormone receptor (Umesono et al. 1988). However, genuine RAR responsive cis-elements have yet to be identified in RAR-responsive genes. A comparison of induction kinetics for different RA-responsive genes in various cell types suggests that the AP- 2 induction in NT2 cells is a secondary, rather than a primary, response to RA; the stimulation of the AP-2 gene promoter may involve a transcription factor(s) that is induced or activated as part of the primary response to RA. In turn, as part of the regulatory cascade that directs RA-induced differentiation, AP-2 may activate a tertiary set of genes required for the differentiation process. Analysis of the transcriptional control regions of the AP-2 gene and those of its target genes will provide insight into these pathways. Potential target genes for AP-2 could include, for example, the Hox-2.1 gene, which is induced in NT2 cells slightly later than AP-2.

Whether our results obtained from NT2 cells are relevant to other RA-responsive tissue culture systems or to cellular differentiation, in general, is an open question, but some evidence suggests that AP-2 does play a role in RA-induced changes of gene expression. For example, 
the stage-specific transcription activation of genes encoding the class I $H$-2 MHC genes, which occurs relatively late in mouse embryogenesis, is also observed during RA-induced differentiation of murine $\mathrm{F} 9 \mathrm{em}$ bryonal carcinoma cells. This activation depends on a highly conserved regulatory element (Kimura et al. 1986; Myazaki et al. 1986) that has been shown to include a binding site for AP-2 (Imagawa et al. 1987; Mitchell et al. 1987). The mouse homolog of the human AP-2 cDNA has been isolated recently and will be useful in clarifying the importance of AP-2 during differentiation of murine cell types (P. Mitchell and R. Tjian, unpubl.).

The finding that the elevated transcription rate of AP-2 is readily reflected in a concomitant increase in AP-2 protein indicates that the mRNA has a relatively short half-life and that its steady-state level is limiting for translation of the protein. Changes in the level of AP-2 gene expression therefore are crucial for the amount of AP-2 transcription factor available. Furthermore, the results of our NT2 cell transfection experiments suggest that the amount of AP-2 protein can be rate limiting for AP-2-binding site-dependent transcription of a reporter gene.

Also we examined whether AP-2-binding site-mediated TPA and cAMP responses in HeLa tk- cells could be explained by concomitant changes in the expression of AP-2. We did not find any significant TPA- and cAMP-dependent inductions in transcription of the AP-2 gene nor in translation of the AP- 2 mRNA. In contrast, the level of AP-2 mRNA and protein was repressed after prolonged exposure of $\mathrm{HeLa} \mathrm{tk}^{-}$cells to TPA. This reduction in the expression of AP-2 is most likely a result of long-term down-regulation of protein kinase $C$, the primary cellular target of TPA (Nishizuka 1986). The physiological significance of this response is unclear, as the endogenous effector molecule of protein kinase $C$, DAG, is short-lived and only transiently available, in contrast to TPA, which is quite stable. These data suggest that AP-2-binding site-mediated TPA and CAMP inductions may occur at the post-translational level, involving modification of AP-2 or associated proteins. Analysis of nuclear extracts on SDS-polyacrylamide gels indicates that potential post-translational modifications of AP-2 do not involve significant alterations in its electrophoretic mobility. It is possible that AP-2 activity is modulated by interactions with other proteins. One potentially important protein-protein interaction has already been demonstrated for AP-2 in its ability to bind SV40 large $T$ antigen in vitro (Mitchell et al. 1987). In this case, $T$ antigen serves as an inhibitor that prevents the binding of AP-2 to DNA. It is conceivable that a cellular analog of T antigen could sequester AP- 2 in an inactive state, with the transcriptionally active form of AP-2 being released in response to stimuli mediated by second messengers such as TPA and/or cAMP. An example of this type of regulation has been reported; transcription factor NF-kB is associated with a specific inhibitor, I-kB, which is released upon TPA induction (Baeuerle and Baltimore 1988b).
There is reasonable correlation between the presence of AP-2-binding sites and transcriptional activation by cAMP for several gene promoters, but it cannot yet be excluded that a DNA-binding protein other than AP-2 is responsible for the TPA and CAMP inductions of AP-2binding site-containing genes. However, unlike several other DNA-binding transcription factors (AP-1, Bohmann et al. 1988; CTF/NFI, Santoro et al. 1988; CREB, Hai et al. 1988), AP-2 does not appear to be part of a polypeptide family with very similar DNA-binding characteristics. Further evidence in support of AP-2 being involved in TPA and cAMP induction comes from its cell type-specific expression: AP-2-binding site-mediated transcriptional inductions and AP-2 gene products are both absent in HepG2 cells (Imagawa et al. 1987; Williams et al. 1988). A more thorough analysis of the role of AP-2 in the mechanism of TPA and cAMP response will be facilitated by transfection of AP-2 expression vectors into mammalian cells.

\section{Materials and methods}

Tissue culture

NT2 and HeLa tk ${ }^{-}$cells were grown in Dulbecco's modified Eagle's medium (DMEM), supplemented with $10 \%$ fetal bovine serum. For differentiation, NT2 cells were trypsinized and seeded at $3 \times 10^{6}$ cells $/ 175-\mathrm{cm}^{2}$ plate. Four hours later, RA $\left(10^{-2} \mathrm{M}\right.$ in ethanol) was added to a final concentration of $10^{-5} \mathrm{M}$ or as indicated, and incubation continued for 1-7 days. For the time points from 4 to 7 days, the cells were split on day 3 and new medium with RA was added. DNA transfections of NT2 cells by the calcium phosphate coprecipitation method were according to standard procedures (Graham and van der $\mathrm{Eb}$ 1973), with minor modifications. Three hours prior to the addition of the precipitate, the medium was replaced with medium containing $50 \mathrm{mM}$ HEPES (pH 7.2). The precipitate containing $30 \mu \mathrm{g}$ of plasmid DNA $/ 175-\mathrm{cm}^{2}$ tissue culture dish was added to the medium and allowed to sediment onto the cells for $5 \mathrm{hr}$. Then the cells were shocked with glycerol $15 \mathrm{ml}$ of $20 \%$ glycerol in PBS for $1 \mathrm{~min} /$, washed twice with PBS, and incubated with fresh medium in the presence or absence of RA $\left(10^{-6} \mathrm{M}\right)$ for $48 \mathrm{hr}$. Cells were harvested by scraping into PBS and collected by quick centrifugation. Cytoplasmic RNA extractions were a modification of Berk and Sharp (1977). RNA from transfected cells was digested with RNase-free DNase (RQ1, Promega), prior to use for RNase protection assays.

HeLa tk ${ }^{-}$cells for drug induction experiments were seeded at $2.5 \times 10^{6}$ to $4 \times 10^{6}$ cells $/ 175-\mathrm{cm}^{2}$ petri dish. Twelve hours later, the medium was replaced with medium containing $0.5 \%$ fetal bovine serum. After 24-hr starvation of serum, drugs were added as $1000 \times$ stock solutions in dimethylsulfoxide (DMSO) to final concentrations of $167 \mathrm{nM}$ TPA; $1 \mu \mathrm{M} \mathrm{A23187;10 \mu \textrm {M }}$ forskolin; and/or $500 \mu \mathrm{M}$ IMX. Control cultures were treated in parallel with solvent alone. RNA was isolated as described above.

\section{Nuclear run-on assays}

Nuclei were isolated according to Carneiro and Schibler (1984), and in vitro elongation of nascent transcripts was performed according to Greenberg and Ziff (1984) in the presence of $[\alpha-32$ P]UTP $(800 \mathrm{Ci} / \mathrm{mmole})$. Single-stranded DNA hybridization probes $(10 \mu \mathrm{g} / \mathrm{slot})$ were immobilized on GeneScreen 
(Amersham), according to the recommendations of the manufacturer, using a slot blot apparatus from Bio-Rad. Filters were prehybridized in $45 \%$ deionized formamide (Fluka p.a.), $50 \mathrm{~mm}$ sodium phosphate $(\mathrm{pH} 7), 1 \%$ bovine serum albumin, $7 \%$ SDS and $1 \mathrm{~mm}$ EDTA for $1 \mathrm{hr}$ at $65^{\circ} \mathrm{C}$ and hybridized under the same conditions for 2 days in hybridization solution containing elongated transcripts at $3.8 \times 10^{6} \mathrm{cpm} / \mathrm{ml}$ in each assay. Filters were washed with several changes of $2 \times$ SST $[1 \times$ SST is 150 $\mathrm{mM} \mathrm{NaCl}, 15 \mathrm{~mm}$ Tris- $\mathrm{HCl}$ (pH 7.5), $2.5 \mathrm{~mm}$ EDTA] and $0.5 \%$ SDS for $30 \mathrm{~min}$ each at $65^{\circ} \mathrm{C}$ and then were washed twice for 10 min in $2 \times$ SST without SDS and treated with RNase A 15 $\mu \mathrm{g} / \mathrm{ml}$ in $2 \times \mathrm{SST}$ ) for $30 \mathrm{~min}$ at $37^{\circ} \mathrm{C}$. Before exposing to X-ray film, filters were washed again for $30 \mathrm{~min}$ at $37^{\circ} \mathrm{C}$ in $2 \times \mathrm{SST}$ containing $0.5 \%$ SDS.

\section{Plasmid constructions}

pHCAT reporter plasmids The HindIII-BamHI fragment containing the CAT gene from SV2CAT (Gorman et al. 1982) was inserted into HindIII-BamHI-cut pUC118 to give pUC118CAT. A 130-bp fragment containing the hMTIIA promoter from -69 to +37 (Karin and Richards 1982) was synthesized with HindIII adaptors and a BgIII site at -77 relative to the hMTIIA start site and inserted into the HindIII site of

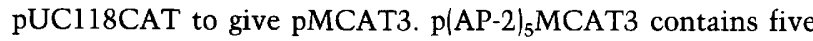
tandem copies of an AP-2-binding site derived from the SV40 enhancer

\section{5'-gatcAAAGTCCCCAGGCTCCCCAGCAGGCA-3' 3'-TTTCAGGGGTCCGAGGGGTCGTCCGTctag-5'}

ligated head to tail into the BglII site of pMCAT3.

Run-on hybridization probes Single-stranded DNA probes were constructed by insertion of cDNA or genomic DNA fragments into the multiple cloning site of $\mathrm{M} 13 \mathrm{mp} 9$ or $\mathrm{mp} 8$, respectively, in such a way that the non-coding strand was represented in the single-stranded phage. Incompatible restriction sites were either filled in with Klenow polymerase $\left(5^{\prime}\right.$ overhangs) or made blunt with T4 polymerase ( 3 ' overhangs) and ligated to the SmaI site in the polylinker of M13. The inserts were CTF [1743-bp NcoI-EcoRI fragment of the CTFI cDNA (Santoro et al. 1988); Sp1 [2551-bp EcoRI-BglII fragment of the Sp1-1 cDNA (Kadonaga et al. 1987)]; $\beta$-actin [human $\beta$-actin cDNA as a $\sim 2000$-bp BamHI fragment from pHF $\beta A-1$ (Gunning et al. 1983)]; c-iun [human c-jun cDNA (Bohmann et al. 1987), 5 ' deletion mutant as a $\sim 1600-$ bp BamHI-EcoRI fragment (gift from D. Bohmann, unpubl.)]; c-myc [human c-myc 1397-bp ThaI-NsiI cDNA fragment that includes second and third exon (Battey et al. 1983)]; AP-2(1) [1284-bp EcoRI-NcoI fragment of the AP-2 cDNA (Williams et al. 1988)]; AP-2(2) [ 1650-bp Sau3A-SacI fragment of a genomic AP-2 isolate that represents intron sequences upstream of the AP-2 protein-coding region (B. Lüscher, unpubl.)].

Templates for riboprobes The plasmids used to produce Spland AP-2-specific riboprobes (Fig. 1A) have been described (Williams et al. 1988). The AP-2 probe used in Figures $1(\mathrm{D})$ and $3(\mathrm{~B})$ was derived from cDNA clone AP2-8 (B. Lüscher and T. Williams, unpubl.): The 179-bp NaeI-PvuII fragment overlapping the amino terminus of the AP-2-coding region was subcloned into the SmaI site of $\mathrm{pBluescript} \mathrm{SK}^{+}$(Stratagene) such that $\mathrm{T} 7$ polymerase would transcribe the noncoding strand. Runoff transcription was performed using DNA template that was linearized in the polylinker with BamHI. The template used for the Hox-2.1-specific probe was kindly provided by C. Hauser and consisted of a $3^{\prime}$-terminal cDNA fragment $(\mathrm{C}$. Hauser, unpubl.) cloned into the EcoRI site of pBluescript $\mathrm{KS}^{+}$(Stratagene). Antisense runoff transcriptions were performed on AccIcut template using T7 RNA polymerase (Stratagene). To quantitate transcripts from the pMCAT3 and p(AP-2) ${ }_{5} \mathrm{MCAT} 3$ expression vectors, the $377-\mathrm{bp} B g I I I-E c o$ RI fragment of pMCAT3 that spans the RNA start site was subcloned between the BamHI and EcoRI sites of pBluescript $\mathrm{SK}^{+}$and runoff transcription was performed with $\mathrm{T} 7$ polymerase using the $\mathrm{XbaI}-$ cut template. To map c-jun mRNA 5' ends, genomic SmaI fragment of c-jun (Bohmann et al. 1987; Hattori et al. 1988), which includes the RNA start sites, was subcloned into the SmaI site of pBluescript $\mathrm{SK}^{+}$. Runoff transcription of antisense probes was performed with the NcoI-cut template using T7 polymerase. Transcriptions by T7 RNA polymerase in the presence of $\left[\alpha^{-32} \mathrm{P}\right] \mathrm{UTP}(400-800 \mathrm{Ci} / \mathrm{mmole})$ were according to the recommendations of the manufacturer (Stratagene).

\section{Western blotting using AP-2 anti-peptide antibody}

The amino-terminal peptide KLTDNIKYEDCEDRHDGTS, corresponding to AP-2 amino acids 4-22 (Williams et al. 1988), was synthesized by Biosearch and coupled to TPPD (Statens Serum Institut) before injection into rabbits. Antibodies directed against AP-2 were partially purified from the rabbit polyclonal antisera by passage over an Affigel-10 column (Bio-Rad) to which the AP-2 peptide had been coupled according to the manufacturer's recommendations. Bound antibody was eluted using $0.1 \mathrm{M}$ glycine- $\mathrm{HCl}(\mathrm{pH} 2.3)$ and immediately neutralized, using one-tenth volume of $2 \mathrm{M}$ Tris- $\mathrm{HCl}(\mathrm{pH} 7.9)$. Western blotting was performed essentially as described by Jackson and Tjian (1989).

\section{Acknowledgments}

We thank the members of Tissue Culture for the maintenance of cell lines, Naoko Tanese for NT2 cell extracts, Steve Jackson and Lorraine Pillus for advice on the production and purification of AP-2 antibodies, Karen Ronan for help in preparing the manuscript, Nic Mermod, Vijay Baichwal, Craig Hauser, and Phil McFadden for comments on the manuscript, and all members of the Tjian lab for helpful discussions. B.L., P.M., and T.W. are supported by grants from the Swiss National Science Foundation (83.637.0.88), the National Institutes of Health (NIH), and the Howard Hughes Medical Institute, respectively. This work was supported, in part, by a grant from NIH to R.T.

\section{References}

Andrews, P.C. 1984. Retinoic acid induces neuronal differentiation of a cloned human embryonal carcinoma cell line in vitro. Dev. Biol. 103: 285-293.

Angel, P., K. Hattori, T. Smeal, and M. Karin. 1988. The jun proto-oncogene is positively autoregulated by its product, Jun/Ap-1. Cell 55: 875-885.

Baeuerle, P.A. and D. Baltimore. 1988a. Activation of DNAbinding activity in an apparently cytoplasmic precursor of the NF-kB transcription factor. Cell 53: 211-217.

1988b. IkB: A specific inhibitor of the NF-kB transcription factor. Science 242: 540-546.

Battey, J., C. Moulding, R. Taub, W. Murphy, T. Stewart, H. Potter, G. Lenoir, and P. Leder. 1983. The human c-myc on- 
cogene: Structural consequences of translocation into the IgH locus in Burkitt lymphoma. Cell 34: 779-787.

Benbrook, D., E. Lernhardt, and M. Pfahl. 1988. A new retinoic acid receptor identified from a hepatocellular carcinoma. Nature 332: 850-853.

Berk, A.J. and P.A. Sharp. 1977. Sizing and mapping of early adenovirus mRNAs by gel electrophoresis of $\mathrm{S} 1$ endonuclease-digested hybrids. Cell 12: 721-732.

Bohmann, D., A. Admon, D.R. Turner, and R. Tjian. 1988. Transcriptional regulation by the AP-1 family of enhancerbinding proteins: A nuclear target for signal transduction. Cold Spring Harbor Symp. Quant. Biol. 53: 695-700.

Bohmann, D., T.J. Bos, A. Admon, T. Nishimura, P.K. Vogt, and R. Tjian. 1987. Human proto-oncogene c-jun encodes a DNA binding protein with structural and functional properties of transcription factor AP-1. Science 238: 1386-1392.

Brand, N., M. Petkovich, A. Krust, P. Chambon, H. de The, A. Marchio, P. Tiollais, and A. Dejean. 1988. Identification of a second human retinoic acid receptor. Nature 332: 850-853.

Carneiro, M. and U. Schibler. 1984. Accumulation of rare and moderately abundant mRNAs in mouse L-cells is mainly post-transcriptionally regulated. I. Mol. Biol. 178: 869-880.

Carpenter, G. 1987. Receptors for epidermal growth factors and other polypeptide mitogens. Annu. Rev. Biochem. 56: 881914.

Castagna, M., Y. Takai, K. Kaibuchi, K. Sano, U. Kikkawa, and Y. Nishizuka. 1982. Direct activation of calcium-activated phospholipid-dependent protein kinase by tumor-promoting phorbol esters. I. Biol. Chem. 257: 7847-7851.

Chiocca, E.A., P.J.A. Davies, and J.P. Stein. 1988. The molecular basis of retinoic acid action. J. Biol. Chem. 263: 1158411589.

Chiu, R., M. Imagawa, R.J. Imbra, J.R. Bockover, and M. Karin. 1987. Multiple cis-and trans-acting elements mediate the transcriptional response to phorbol esters. Nature 329: 648651.

Comb, M., N.C. Birnberg, A. Seasholtz, E. Herbert, and H.M. Goodman. 1986. A cyclic AMP- and phorbol ester-inducible DNA element. Nature 323: 353-356.

Comb, M., N. Mermod, S.E. Hyman, J. Pearlberg, M.E. Ross, and H.M. Goodman. 1988. Proteins bound at adjacent DNA elements act synergistically to regulate human proenkephalin CAMP inducible transcription. EMBO /. 7:37933805.

Evans, R.M. 1988. The steroid and thyroid hormone receptor superfamily. Science 240: 879-895.

Giguere, V., E.S. Ong, P. Segui, and R.M. Evans. 1987. Identification of a receptor for the morphogen retinoic acid. Nature 330: 624-629.

Gonzalez, G.A., K.K. Yamamoto, W.H. Fischer, D. Karr, P. Menzel, W. Biggs III, W.W. Vale, and M.R. Montminy. 1989. A cluster of phosphorylation sites on the cyclic AMP-regulated nuclear factor CREB predicted by its sequence. Nature 337: 749-752.

Gorman, C.M., L.F. Moffat, and B.H. Howard. 1982. Recombinant genomes which express chloramphenicol acetyltransferase in mammalian cells. Mol. Cell. Biol. 2: 1044-1051.

Graham, F.L. and A.J. van der Eb. 1973. A new technique for the assay of infectivity of human adenovirus 5 DNA. Virology 52: $56-467$.

Greenberg, M.E. and E.B. Ziff. 1984. Stimulation of 3T3 cells induces transcription of the c-fos proto-oncogene. Nature 311: 433-438.

Gunning, P., P. Ponk, H. Okayama, J. Engel, H. Blau, and L. Kedes. 1983. Isolation and characterization of full length cDNA clones for human $\alpha-, \beta$-, and $\gamma$-actin mRNAs: Skel- etal but not cytoplasmic actins have an amino-terminal cysteine that is subsequently removed. Mol. Cell. Biol. 3: 787795.

Hai, T., F. Liu, E.A. Allegretto, M. Karin, and M.R. Green. 1988. A family of immunologically related transcription factors that includes multiple forms of ATF and AP-1. Genes Dev. 2: $1216-1226$.

Hattori, K., P. Angel, M.M. LeBeau, and M. Karin. 1988. Structure and chromosomal localization of the functional intronless human Jun protooncogene. Proc. Natl. Acad. Sci. 85: $9148-9152$.

Hauser, C.A., A.L. Joyner, R.D. Klein, T.K. Learned, G.R. Martin, and R. Tjian. 1985. Expression of homologous homeo-box-containing genes in differentiated human teratocarcinoma cells and mouse embryos. Cell 43: 19-28.

Hoeffler, J.P., T.E. Meyer, Y. Yun, J.L. Jameson, and J.F. Habener. 1988. Cyclic AMP-responsive DNA-binding protein: Structure based on a cloned placental cDNA. Science 242: $1430-1432$.

Hyman, S.E., M. Comb, J. Pearlberg, and H.M. Goodman. 1989. An AP-2 element acts synergistically with the cyclic AMPand phorbol ester-inducible enhancer of the human proenkaphalin gene. Mol. Cell. Biol. 9: 321-324.

Hyman, S.E., M. Comb, Y-S. Lin, J. Pearlberg, M.R. Green, and H.M. Goodman. 1988. A common trans-acting factor is involved in transcriptional regulation of neurotransmitter genes by cyclic AMP. Mol. Cell. Biol. 8: 4225-4233.

Imagawa, M., R. Chiu, and M. Karin. 1987. Transcription factor AP-2 mediates induction by two different signal-transduction pathways: protein kinase $\mathrm{C}$ and cAMP. Cell 51: 251260.

Jackson, S.P. and R. Tjian. 1989. Purification and analysis of RNA polymerase II transcription factors by using wheat germ agglutinin affinity chromatography. Proc. Natl. Acad. Sci. 86: $1781-1785$.

Kadonaga, J.T., K.R. Carner, F.R. Masiarz, and R. Tjian. 1987. Isolation of cDNA encoding transcription factor $\mathrm{Spl}$ and functional analysis of the DNA binding domain. Cell 51: 1079-1090.

Karin, M. and R.I. Richards. 1982. Human metallothionein genes-Primary structure of the metallothionein-II gene and a related processed gene. Nature 299: 797-802.

Kimura, A., A. Israël, O. LeBail, and P. Kourilsky. 1986. Detailed analysis of the mouse $\mathrm{H}-2 \mathrm{~Kb}$ promoter: enhancer-like sequences and their role in the regulation of class I gene expression. Cell 44: 261-272.

LaRosa, G.J. and L.J. Gudas. 1988. Early retinoic acid-induced F9 teratocarcinoma stem cell gene ERA-1: Alternate splicing creates transcripts for a homeobox-containing protein and one lacking the homeobox. Mol. Cell. Biol. 8: 3906-3917.

Lee, W., A. Haslinger, M. Karin, and R. Tiian. 1987. Activation of transcription by two factors that bind promoter and enhancer sequences of the human metallothionein gene and SV40. Nature 325: $368-372$.

Mitchell, P.J. and R. Tiian. 1989. Transcriptional regulation in mammalian cells by sequence-specific DNA binding proteins. Science 245: 371-378.

Mitchell, P.J., C. Wang, and R. Tiian. 1987. Positive and negative regulation of transcription in vitro: Enhancer-binding protein AP-2 is inhibited by SV40 T antigen. Cell 50: 847861.

Miyamoto, M., T. Fujita, Y. Kimura, M. Maruyama, H. Harada, Y. Sudo, T. Miyata, and T. Taniguchi. 1988. Regulated expression of a gene encoding a nuclear factor, IRF-1, that specifically binds to IFN- $\beta$ gene regulatory elements. Cell 54: $903-913$ 
Miyazaki, J., E. Appella, and K. Ozato. 1986. Negative regulation of the major histocompatibility class I gene in undifferentiated embryonal carcinoma cells. Proc. Natl. Acad. Sci. 83: 9537-9541.

Montminy, M.R. and L.M. Bilezikjian. 1987. Binding of a nuclear protein to the cyclic AMP responsive element of the somatostatin gene. Nature 328: 175-178.

Nishizuka, Y. 1986. Studies and perspectives of protein kinase C. Science 233: 305-312.

Petkovich, M., N.J. Brand, A. Krust, and P. Chambon. 1987. A human retinoic acid receptor which belongs to the family of nuclear receptors. Nature 330: 444-450.

Rickles, R.J., A.L. Darrow, and S. Strickland. 1989. Differentiation-responsive elements in the $5^{\prime}$ region of the mouse tissue plasminogen activator gene confer two-stage regulation by retinoic acid and cyclic AMP in teratocarcinoma cells. Mol. Cell. Biol. 209: 1691-1704.

Roesler, W.J., G.R. Vandenbark, and R.W. Hanson. 1988. Cyclic AMP and the induction of eukaryotic gene transcription. $J$. Biol. Chem. 263: 9063-9066.

Rosenthal, A., S. Wright, H. Cedar, R. Flavell, and F. Grosveld. 1984. Regulated expression of an introduced MHC H-2K $\mathrm{K}^{\mathrm{bm} 1}$ gene in murine embryonal carcinoma cells. Nature 310: 415-418.

Santoro, C., N. Mermod, P.C. Andrews, and R. Tjian. 1988. A family of human CCAAT-box-binding proteins active in transcription and DNA replication: Cloning and expression of multiple cDNAs. Nature 334: 218-224.

Sen, R. and D. Baltimore. 1986. Inducibility of $\mathbf{k}$ immunoglobulin enhancer-binding protein NF-kB by a post-translational mechanism. Cell 47: 921-928.

Sleigh, M.J. and T.J. Lockett. 1985. SV40 enhancer activation during retinoic acid-induced differentiation of $\mathrm{F} 9$ embryonal carcinoma cells. EMBO I. 4: 3831-3837.

Strickland, S. and V. Mahdavi. 1978. The induction of differentiation in teratocarcinoma stem cells by retinoic acid. Cell 15: 393-403.

Thaller, C. and G. Eichele. 1987. Identification and spatial distribution of retinoids in the developing chick limb bud. $\mathrm{Na}$ ture 327: 625-628.

Treisman, R. 1986. Identification of a protein-binding site that mediates transcriptional response of the $c$-fos gene to serum factors. Cell 46: 567-574.

Umesono, K., V. Giguere, C.K. Glass, M.G. Rosenfeld, and R.M. Evans. 1988. Retinoic acid and thyroid hormone induce gene expression through a common responsive element. Nature 336: $262-265$.

Williams, T., A. Admon, B. Lüscher, and R. Tjian. 1988. Cloning and expression of AP-2, a cell-type-specific transcription factor that activates inducible enhancer elements. Genes Dev. 2: 1557-1569.

Yamamoto, D.R. 1985. Steroid receptor regulated transcription of specific genes and gene networks. Annu. Rev. Genet. 19: 209-252. 


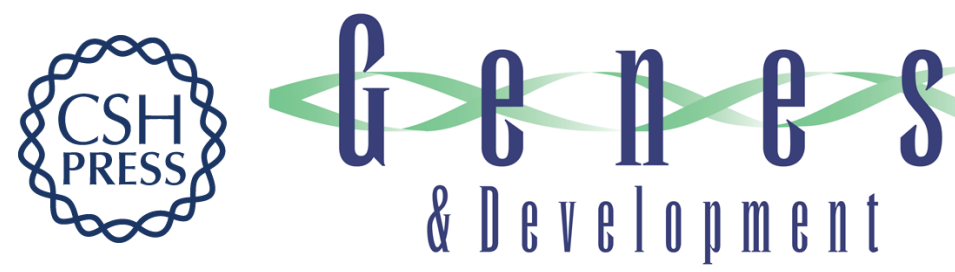

\section{Regulation of transcription factor AP-2 by the morphogen retinoic acid and by second messengers.}

B Lüscher, P J Mitchell, T Williams, et al.

Genes Dev. 1989, 3:

Access the most recent version at doi:10.1101/gad.3.10.1507

References This article cites 56 articles, 20 of which can be accessed free at:

http://genesdev.cshlp.org/content/3/10/1507.full.html\#ref-list-1

License

Email Alerting

Service

Receive free email alerts when new articles cite this article - sign up in the box at the top right corner of the article or click here.

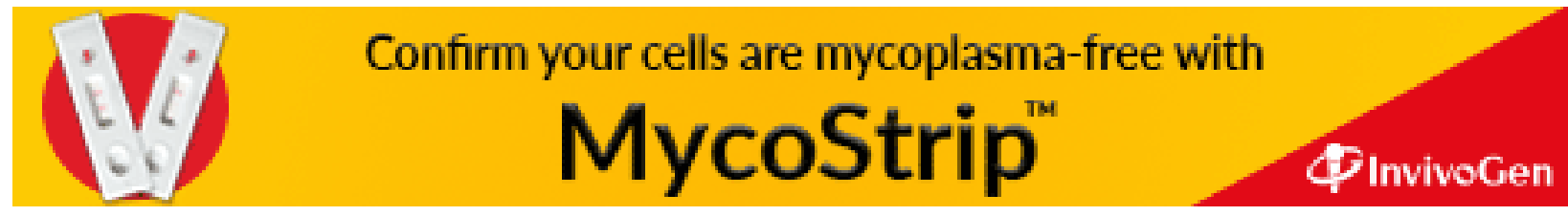

